\title{
Remobilisation and Fate of Sulphur in Indian Mustard (Brassica juncea. L) ${ }^{\dagger}$
} Priyakshee Borpatragohain *, Graham J. King, Terry Rose, Lei Liu, Tobias Kretzschmar, Bronwyn Barkla
and Carolyn Raymond

Southern Cross Plant Science, Southern Cross University, Lismore, NSW 2480, Australia; graham.king@scu.edu.au (G.J.K.); terry.rose@scu.edu.au (T.J.R.); ben.liu@scu.edu.au (L.L.); tobias.kretzschmar@scu.edu.au (T.K.); bronwyn.barkla@scu.edu.au (B.J.B.); carolyn.raymond@scu.edu.au (C.R.)

* Correspondence: priyakshee.borpatragohain@scu.edu.au

+ Presented at the third International Tropical Agriculture Conference (TROPAG 2019), Brisbane, Australia, 11-13 November 2019.

Published: 31 December 2019

\begin{abstract}
Understanding the basis of sulphur (S) use efficiency in higher $S$ requiring crops such as brassicas can help develop more cost-effective cultivars. Oleriferous brassicas sequester reduced $S$ in the mature seeds mainly as secondary metabolite-glucosinolate (GSL) and seed storage proteins (SSP). Glucosinolates have a wide range of positive aspects in food production, human nutrition and plant defence, and SSPs are a potential source of high quality vegetable proteins for human and livestock consumption. We carried out a developmental $S$ audit to establish the net fluxes of $S$ in two lines of B. juncea mustard where the level of seed GSL differed. We quantified S pools (sulphate, GSL and total S) in different organs at multiple growth stages until maturity. We have established that leaf $S$ components accumulated as primary $S$ sinks at early developmental stages in condiment type B. juncea become remobilised as a secondary $S$ source to meet the demand of GSL as the dominant seed $S$ sink at maturity. Our evidence for $S$ remobilisation from leaves as primary $S$ sink suggests that up or down regulation of signalling molecules which mediate between secondary $S$ sinks and sources may help modulate economically valuable S compounds in brassica seed.
\end{abstract}

Keywords: sulphate; glucosinolate; seed storage proteins; source; sink; brassica; canola; remobilization

Author Contributions: P.B.: experimental analysis; P.B., G.J.K., T.J.R.: conceptualization, methodology, visualization, writing; L.L., T.K., B.J.B.: methodology; C.R.: formal statistical analysis.

Funding: Australian Research Council, Linkage LP170101062, Australian Mustard Oil Pty. Ltd.

Acknowledgments: B. Cheng and I. Parkin (AAFC, Canada) for providing seeds of homozygous B. juncea.

Conflicts of Interest: The authors declare no conflict of interest.

(C) 2019 by the authors. Licensee MDPI, Basel, Switzerland. This article is an open access article distributed under the terms and conditions of the Creative Commons Attribution (CC BY) license (http://creativecommons.org/licenses/by/4.0/). 